\title{
The role of Neu1 in the protective effect of dipsacoside B on acetaminophen-induced liver injury
}

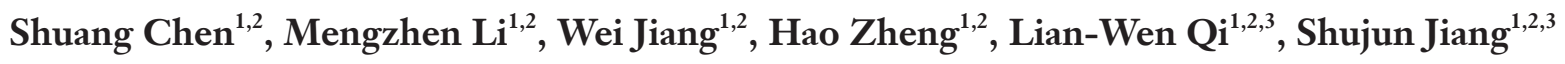 \\ ${ }^{1}$ State Key Laboratory of Natural Medicines, ${ }^{2}$ School of Traditional Chinese Pharmacy, ${ }^{3}$ The Clinical Metabolomics Center, China Pharmaceutical \\ University, Nanjing, China \\ Contributions: (I) Conception and design: S Jiang, LW Qi; (II) Administrative support: None; (III) Provision of study materials or patients: None; \\ (IV) Collection and assembly of data: S Jiang, S Chen, H Zhen, M Li; (V) Data analysis and interpretation: S Jiang, S Chen, H Zhen, M Li; (VI) \\ Manuscript writing: All authors; (VII) Final approval of manuscript: All authors. \\ Correspondence to: Shujun Jiang; Lian-Wen Qi. State Key Laboratory of Natural Medicines, The Clinical Metabolomics Center, School of Traditional \\ Chinese Pharmacy, China Pharmaceutical University, Nanjing, China. Email: fairyjsj@163.com; Qilw@cpu.edu.cn.
}

Background: Pharmacological induction of autophagy can protect against acetaminophen (APAP) induced acute liver failure (ALF) by removing APAP adducts (APAP-AD), but its mechanism is not well understood. Hepatoprotective effect of saponins from traditional Chinese medicine has attracted widespread attention from all over the world. The content of saponins in Lonicerae Flos (Shanyinhua in Chinese) is up to 15-25\%. Dipsacoside B (DB) is a common bioactive ingredient of different Shanyinhua, but its hepatoprotective effect and mechanism are still unknown. The present investigation aimed to study the benefit of DB in APAPinduced hepatotoxicity mouse model and different cell model.

Methods: Mice were treated with DB by intraperitoneal injection $1 \mathrm{~h}$ before treated with $500 \mathrm{mg} / \mathrm{kg}$ APAP, which caused ALF after $4 \mathrm{~h}$. HepG2 cells were treated with DB for $1 \mathrm{~h}$ before treated with $10 \mathrm{mM}$ APAP for 12 h. Hepatotoxicity was assessed via ALT and AST. Neuraminidase 1 (Neu1), lysosomal autophagy marker LC3 and P62 were examined by western blot. Neu1 activity was assayed using its substrate 2-(4-methylumbelliferyl)-D-N-acetylneuraminic acid. Apoptosis level was examined by TUNEL and caspase 3 activity. Molecular docking was used to predict the interaction between DB and protein Neu1.

Results: Our results demonstrated that pretreatment with $0.5 \mu \mathrm{M} \mathrm{DB}$ (in vitro) and $50 \mathrm{mg} / \mathrm{kg} \mathrm{DB}$ (in vivo) respectively reversed increased level of AST and ALT induced by APAP. Histopathological examinations showed reduced necrosis and apoptosis in the liver of DB-treated APAP mice. DB promoted the removal of APAP-AD by lysosomal autophagy. These effects were associated with significant decrease in the level of Neuraminidase 1 (Neu1), a negative regulator of lysosomal exocytosis. Molecular docking results showed that DB could bind to Neu1 protein (binding energy =-7.86 kcal/mol). Akt/mTOR-mediated autophagy and inhibition of apoptosis may be the main mechanisms for the hepatoprotective effects of DB in acetaminophen-induced liver injury.

Conclusions: These data indicate that DB alleviated hepatotoxicity caused by APAP at least in part via Neu1 inhibition, Akt/mTOR pathway is involved in the detoxification effect of DB on acetaminopheninduced hepatotoxicity.

Keywords: Acetaminophen (APAP); acute liver failure (ALF); dipsacoside B; neuraminidase 1

Submitted Nov 26, 2019. Accepted for publication Jun 03, 2020.

doi: 10.21037/atm-19-3850

View this article at: http://dx.doi.org/10.21037/atm-19-3850 


\section{Introduction}

Acetaminophen (APAP) is currently widely used as an antipyretic and analgesic drug, but an overdose can cause severe liver injury and even acute liver failure (ALF) in animals and humans (1). At therapeutic doses, $90 \%$ of APAP binds to glucuronide and sulfuric acid to form nontoxic APAP complex, and excreted by the kidneys (2). The remaining part forms a reactive metabolite, $\mathrm{N}$-acetylp-benzoquinone imine (NAPQI) via the activity of cytochrome P450 enzymes. NAPQI then conjugates with hepatic glutathione (GSH), and is consequently secreted into the bile without damage (3). Overdose of APAP can generate excess NAPQI, which deplete cellular GSH and cause APAP protein adduct (APAP-AD) formation, resulting in liver injury as result. NAPQI, as APAP metabolite, can react with protein in mitochondria to form APAP-AD, which results in mitochondrial damage causing hepatic cell necrosis and liver damage $(4,5)$.

Autophagy can selectively remove cytosolic macromolecules and damaged organelles, thereby preventing mitochondrial damage-induced cell death $(6,7)$. Recent reports indicated PI3K/Akt/mTOR signaling pathway regulated autophagy and apoptosis in different tissue injury $(8,9)$. Accumulating evidence indicate that pharmacological induction of autophagy can protect against APAP-induced liver injury by removing APAP-AD $(10,11)$, but the underlying mechanism remains unclear. Neuraminidase 1 (Neu1), a sialidase (SA), is widely found on the cell membrane and in lysosomes. It desialylates sialo-glycoconjugates by removing their terminal sialic acid residues (12). Most of the studies on Neu1 mainly focused on hepatic glucose and lipid metabolism $(13,14)$, but very little is known about its role in drug-induced ALF. Autophagy starts with the formation of the phagophore, followed by autophagosome, and then fuses with lysosomes to form autolysosomes, wherefrom the contents are degraded by lysosomal enzymes $(6,15)$. Lysosomal function and acidification are fundamental mechanisms for autophagosome-lysosome fusion. Lysosomal membrane protein 1 (LAMP-1) is predominantly localized in lysosomal membrane (LM), which protects LM from self-digestion, plays important physiological roles in maintaining lysosomes structures and functions (16). It has been reported that Neu1 negatively mediated lysosomal exocytosis in hematopoietic cells by LAMP-1 desialyation (17). Whether Neu1 can mediate drug-induced liver damage by affecting lysosomal exocytosis has not been reported yet.
$\mathrm{N}$-acetyl-L-cysteine (NAC) is the first line detoxification drug for treating APAP-induced ALF in the initial rise in toxicity, but lots of patients present to the hospital after this stage (18). Furthermore, Lack of suitable biomarkers which can indicate progression of liver failure and provide liver transplantation operative basis (19). Therefore it is urgent to explore novel candidates and find new target for APAPinduced hepatotoxicity treatment.

Saponin extracts from traditional Chinese medicine have been widely reported to be resistant to drug-induced acute liver damage. From the chemical structural point of view, most saponins with hepatoprotective effects are triterpenoids, such as Ginseng saponins, saikosaponins, aescin etc. (20-22). The aforementioned studies suggest that hepatoprotection may be a common effect among saponins. The content of saponins in Lonicerae Flos (Shanyinhua in Chinese) is up to $15 \%$, with regard to reported protective effects against $\mathrm{CC1}_{4^{-}}$and $\mathrm{D}$-galactosamine-induced liver injury (23). Dipsacoside B (DB) is a common triterpenoid bioactive ingredient of different Lonicerae Flos without rhamnose in its branch chain compared to akebia saponin $\mathrm{D}$ (ASD). ASD is reported to alleviate hepatic steatosis via increased autophagic flux in both $o b / o b$ mice and Buffalo rat liver cells (24). However, the hepatoprotective potential of $\mathrm{DB}$ remains unclear.

In the present study, we found that $\mathrm{DB}$ ameliorated APAP-induced hepatotoxicity via promoted autophagy and alleviated apoptosis, which contributed to the alteration of Akt/mTOR signal pathway. Upregulation of Neu1 caused by APAP was inhibited by DB, which can be a potential target for ALF therapy. Our data indicate that DB has the capacity to prevent APAP-induced hepatotoxicity due to autophagy activation and anti-apoptosis effects.

We present the following article in accordance with the ARRIVE reporting checklist (available at http://dx.doi. org/10.21037/atm-19-3850).

\section{Methods}

\section{Reagents and chemicals}

Assay kits for alanine aminotransferase (ALT), aspartate aminotransferase (AST), and glutathione disulfide (GSSG) were purchased from Nanjing Jiancheng Bioengineering Institute (Nanjing, China). Neu1 antibody was purchased from signal way antibody (Baltimore, USA). Antibodies LC3, P62, LAMP1, Akt, phosphorylate-Akt, mTOR, phosphorylate-mTOR were ordered from Cell Signaling 
Technology (Danvers, America). Acetaminophen (APAP) was obtained from Aladdin (Shanghai, China). Dipsacoside B (PubChem CID: 21627940) was bought from Chengdu Alfa Biothechnology Co., Ltd (Chengdu, China). 2-(4-methylumbelliferyl) -D-N-acetylneuraminic acid (4MU-NeuAc) was obtained from Sigma (St. Louis, MO, USA), Caspase 3 Activity Assay Kit (Beyotime Biotechnology, China) were purchased from Beyotime Biotechnology.

\section{Experimental animals}

Eight weeks old male C57BL/6J (18-22 g, RRID: IMSR_ JAX:000664) mice were housed in a temperature-controlled $\left(23-25{ }^{\circ} \mathrm{C}\right)$ and humidity $40-60 \%$ specific pathogen-free facility with free access to standard food and water under $12 \mathrm{~h}$ light-12 h dark cycle. All mice were provided by the Laboratory Animal Center of Nanjing Qinglongshan (Nanjing, China). Mice were randomly assigned to five groups ( $\mathrm{n}=10$ each group): (I) Normal control group: treated with saline by intraperitoneal injection, (II) APAP induced group: treated with $500 \mathrm{mg} / \mathrm{kg}$ APAP by intraperitoneal injection, (III) APAP + DB group: $25 \mathrm{mg} / \mathrm{kg}$ DB was given by intraperitoneal injection $1 \mathrm{~h}$ before treated with $500 \mathrm{mg} / \mathrm{kg}$ APAP, (IV) APAP + DB group: $50 \mathrm{mg} / \mathrm{kg}$ DB was given by intraperitoneal injection $1 \mathrm{~h}$ before treated with $500 \mathrm{mg} / \mathrm{kg}$ APAP, (V) APAP + OS group: $25 \mathrm{mg} / \mathrm{kg}$ OS was given by intraperitoneal injection $1 \mathrm{~h}$ before treated with $500 \mathrm{mg} / \mathrm{kg}$ APAP. The number of dead mice was recorded in every $2 \mathrm{~h}$ after APAP with or without DB injection, the survival rate of the mice was evaluated within $24 \mathrm{~h}$. After APAP administration at $4 \mathrm{~h}, 6-8$ animals were anesthetized and sacrificed for experimental analysis. All experiments were approved by the Animal Ethics Committees of China Pharmaceutical University and performed in adherence with the Guide for the Care and Use of Laboratory Animals of China Pharmaceutical University.

\section{Biochemical parameters}

Serum ALT and AST activity after $4 \mathrm{~h}$ of APAP induction were measured by ALT and AST reagent kit (Nanjing Jiancheng Bioengineering Institute, Nanjing, China). Oxidized glutathione (GSSG) content in HepG2 cells after $12 \mathrm{~h}$ of APAP treatment was measured by GSSG reagent kit (Nanjing Jiancheng Bioengineering Institute, Nanjing, China). Serum Caspase 3 activity was examined by Caspase 3 Activity Assay Kit (Beyotime Biotechnology, China).

\section{Sialidase activity assay}

We used the protocol described by Alexey V. Pshezhetsky and Michel Potier with minor modifications (25). Freshly isolated liver $(100 \mathrm{mg})$ or cells $\left(10^{6}\right)$ were homogenized 5 times by sonication $(50 \mathrm{hz}, 5 \mathrm{~s} /$ time $)$ in $200 \mu \mathrm{L} \mathrm{H}_{2} \mathrm{O}$, and incubated with $0.25 \mathrm{mM} 4 \mathrm{MU}-\mathrm{NeuAc}$ (Sigma, M8639) at $37^{\circ} \mathrm{C}$ for $1 \mathrm{~h}$ in $\mathrm{Na}$-acetate buffer $(\mathrm{pH}=4.6) ; 0.4 \mathrm{M}$ glycine buffer ( $\mathrm{pH}=10.4$ ) was used to terminate the reaction. Fluorescence of liberated 4-methylumbelliferone (ex. $365 \mathrm{~nm}$, em. $450 \mathrm{~nm}$ ) was measured using a Thermofisher Multiskan ${ }^{\mathrm{TM}} \mathrm{FC}$ spectrofluorometer.

\section{Quantitative real-time polymerase chain reaction (qRT- PCR)}

High-quality total RNA from liver and HepG2 cells were isolated via extraction with TRIeasyTM Total RNA Extraction Reagent (10606ES60, Yeasen, China). cDNA was synthesized using Hifair ${ }^{\circledR}$ II 1st Strand cDNA Synthesis SuperMix for qPCR (gDNA digester plus) (11123ES60, Yeasen, China). The primers used for mice Neu1, mice 36B4, human Neu1, and human HPRT were as follows: mNeu1-F 5'-CCAACACCTTTGCTTCCTTGG-3' (Forward) and 5'-AGGGTAATGGGGAGCC TGAGT-3' (Reverse); m36b4-F 5'- AGCCTAAGATGAGCGCAAGT-3' (Forward) and 5'- TTACTAGGCAGATGGCCACA-3' (Reverse); hNeu1-F 5'- TGTGACCTTC ACCCTGAGC-3' (Forward) and 5'- TCGCAGGGTCAGGTTCACTC-3' (Reverse); hHPRT-F 5'- ACCAGTCAACAGGGGACATAAAAG-3' (Forward) and 5'- GTCTGCATTGTTTGCCAGTGTC -3' (Reverse). Quantitative RT-PCR for each gene was performed using Hieff ${ }^{\mathrm{TM}}$ qPCR SYBR $^{\circledR}$ Green Master Mix (No Rox) (11201ES03, Yeasen, China) in a Biorad CFX96 Touch real time PCR system (Biorad, USA.). The relative abundance of target gene transcripts was normalized via 36b4 (mice) or HPRT (human) expression.

\section{Histological analysis and immunobistochemistry (IHC) and TUNEL assay}

Livers were collected post $4 \mathrm{~h}$ intervention in different groups. Liver was fixed in $4 \%$ paraformaldehyde (PFA), sections $(5 \mu \mathrm{m})$ were created and stained with hematoxylin and eosin according to standard procedures. Immunohistochemistry (IHC) was performed on paraffin sections as previously described (26). The TUNEL assay was performed by apoptosis detection kits (Beyotime 
Biotechnology, China) to detect apoptosis in liver tissues according to the manufacturer's instructions. Images were captured by a Leica Upright Microscope DM2500, and calculated semi-quantitatively at magnification $\times 400$ with Image Pro Plus software.

\section{Cell culture}

The human hepatoma cell line HepG2 (ATCC number:HB-8065 ${ }^{\mathrm{TM}}$ ) was kindly supplied by Stem Cell Bank, Chinese Academy of Sciences. HepG2 cells were supported in Minimum Essential Medium (MEM, KGM31600-500, KeyGEN BioTECH) supplemented with $10 \%$ fetal bovine serum (FBS). Cells were maintained at $37^{\circ} \mathrm{C}$ in a humidified atmosphere with $5 \% \mathrm{CO}_{2}$.

\section{Western blotting}

The livers and cells were homogenized in protein lysis buffer to harvest total protein (P0013, Beyotime Biotechnology). The lysates were centrifuged at $12,000 \mathrm{~g}$ for $15 \mathrm{~min}$ at $4{ }^{\circ} \mathrm{C}$. Protein concentrations in supernatants were determined with the enhanced BCA Protein Assay Kit (P0009, Beyotime Biotechnology). Proteins in same amount were separated by $12 \%$ sodium dodecyl sulfate polyacrylamide gel electrophoresis (SDS-PAGE). The membrane was further stained with Ponceau red (Nanjing Jiancheng Bioengineering Institute, Nanjing, China) to analyze APAP-AD.

\section{Molecular docking}

Search for the amino acid sequence of human NEU1 (Gene ID: 4758) was conducted. A homology model of human Neu 1 was built at SWISS-MODEL website. Molecular docking of dipsacoside B (PubChem CID: 21627940) and Neu1 was performed by AutoDock (version 4.2.6). A genetic algorithm was performed 100 times to obtain 100 docking conformations, from which the best conformation was selected.

\section{Statistical analysis}

Statistically significant differences between control group and experimental group are presented as the means \pm SD. All data were analyzed by one-way ANOVA (when three groups are compared) or repeated measurement ANOVA (for time course data) and unpaired Student's t-test. $\mathrm{P}<0.05$ was considered statistically significant.

\section{Results}

\section{Protective effect of DB treatment against APAP-induced bepatotoxicity}

To investigate the hepatoprotective effect of DB (Figure 1A) in mice treated with an overdose of APAP $(500 \mathrm{mg} / \mathrm{kg})$ for $4 \mathrm{~h}$, we checked the circulating level of ALT and AST which were widely used as biochemical markers for the evaluation of hepatic injury. As shown in Figure 1B, serum ALT and AST levels were dramatically raised in the APAP group compared with the control group $(\mathrm{P}<0.001)$. However, DB pretreatment significantly reduced the serum ALT $(\mathrm{P}<0.01)$ and AST $(\mathrm{P}<0.05)$ levels than in the APAP group (Figure $1 B$ ). To investigate the effects of DB on APAPinduced mortality, the survival rate was observed every $2 \mathrm{~h}$ within $24 \mathrm{~h}$ after DB treatment. We found $50 \mathrm{mg} / \mathrm{kg}$ DB pretreatment could significantly improve the survival rate of APAP-induced mice. Mice in APAP group began to die at $14 \mathrm{~h}$, and the final survival rate was $20 \%$, while $50 \mathrm{mg} / \mathrm{kg}$ DB increased the survival rate to $50 \%$ (Figure 1C). Histopathology of liver tissues was performed using H\&E staining. Centrilobular necrosis in the necrotic area was markedly increased in APAP-treated mice compared to control mice (Figure 1D). In addition, we also found that DB pretreatment can partly suppress the hepatotoxicity caused by LPS/D-GalN in mice. The elevations of ALT and AST were both reduced but without significance by DB pretreatment for LPS/D-GalN mice (Figure $S 1 A, S 1 B)$, and inflammatory cell infiltration was decreased (Figure S1C). Those results indicated that DB has hepatoprotective effect on APAP-induced liver injury.

\section{Effects of pretreatment with DB on autophagy}

Emerging evidence indicate that autophagy is an important protective mechanism against APAP-induced Liver injury $(4,7,27)$. To study whether DB pretreatment protects against APAP-induced ALF via autophagy activation, the levels of autophagy marker LC3 and P62 were examined in liver of APAP-induced mice. Our data showed that pretreatment with DB increased the ratio of LC3 II/LC3-I in liver of APAP-treated mice, while P62 level slightly reduced (Figure 2A), which indicated that DB promoted autophagy in APAP mice. Immunohistochemistry confirmed that autophagy was raised in APAP-treated 


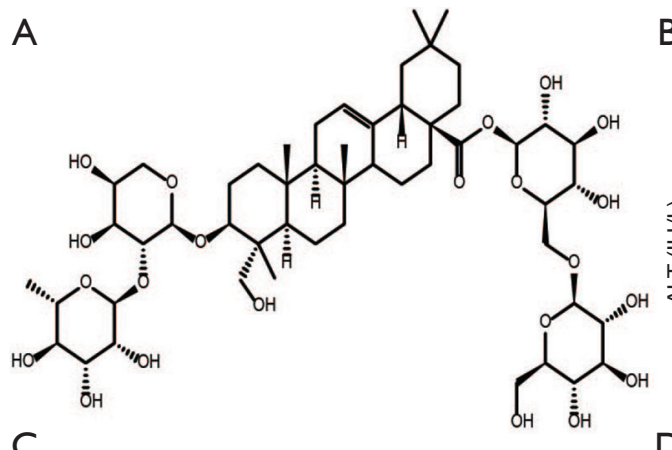

B
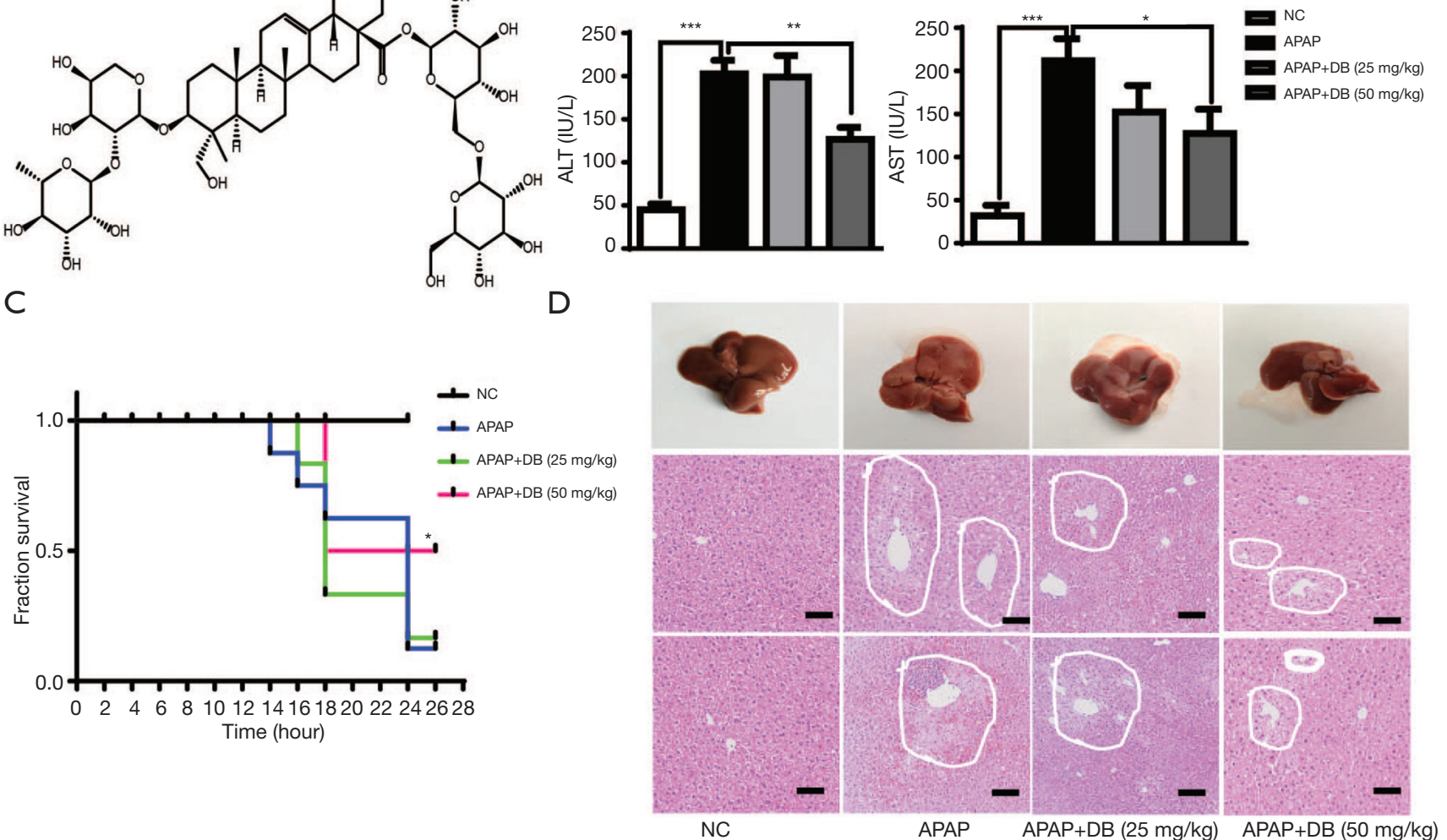

Figure 1 Protective effect of DB on liver histopathological alterations in APAP induced mice. (A) The chemical structure of Dipsacoside B (DB). (B) Serum ALT and AST levels in APAP-treated mice with or without DB were detected after APAP treatment for $4 \mathrm{~h}$. (C) Survival rate of mice were pretreated with DB by intraperitoneal injection for $1 \mathrm{~h}$ before APAP induction. (D) Representative liver histopathology with hematoxylin/ eosin staining of APAP-induced liver injury in mice, assessed by images capture (Scale bar $=100 \mu \mathrm{m}) . \mathrm{n}=6-8,{ }^{*}, \mathrm{P}<0.05 ;{ }^{* *} \mathrm{P}<0.01 ;{ }^{* * *}, \mathrm{P}<0.005$.

mice (Figure 2B). The predominant forms of APAP-AD were $34 \mathrm{kDa}-60 \mathrm{kDa}$, increased after $1 \mathrm{~h}$ treatment with APAP, reached a maximum around $2 \mathrm{~h}$, declined at 6-24 h with overdose of APAP, which is the critical initiation event for mitochondrial damage involved in hepatic necrosis with overdose of APAP (11). Ponceau red staining qualitatively revealed that $\mathrm{DB}$ protected against the APAPinduced hepatic necrosis by increasing APAP-AD removal (Figure 2C).

\section{Protective effect of DB treatment against APAP induced HepG2 cell}

NAPQI, the toxic metabolite of acetaminophen, binds to GSH covalently and forms glutathione disulfide (GSSG), causing GSH depletion (3). In order to determine whether DB affected the metabolism of acetaminophen, we examined the GSSG level in APAP-treated HepG2 cell. As expected, $0.5 \mu \mathrm{M}$ DB potently inhibited the increase of GSSG caused by $10 \mathrm{mM}$ APAP (Figure 3A). Meanwhile, enhancement of ALT level was markedly prevented in $0.5 \mu M$ DB-treated HepG2 cell pretreated with $10 \mathrm{mM}$ APAP (Figure 3B). To investigate whether DB can alleviate APAP-induced hepatotoxicity in HepG2 cells by autophagy, we examined LC3-II and P62 levels. We found that LC3II was significantly increased in APAP-treated HepG2 cells with $0.5 \mu \mathrm{M}$ DB treatment, while P62 was reduced (Figure 3C). To confirm the hepatoprotective effect of DB, we examined the autophagy in two other liver cell linesHuh7 and SMMC-7721 HCC cells treated by APAP. Our results show that $\mathrm{DB}$ can promote autophagy no significant change of LC3 II and P62 in these cells (Figure S2A,S2B). These results also showed that DB could ameliorate APAPinduced ALF by autophagy in HepG2 cells. 

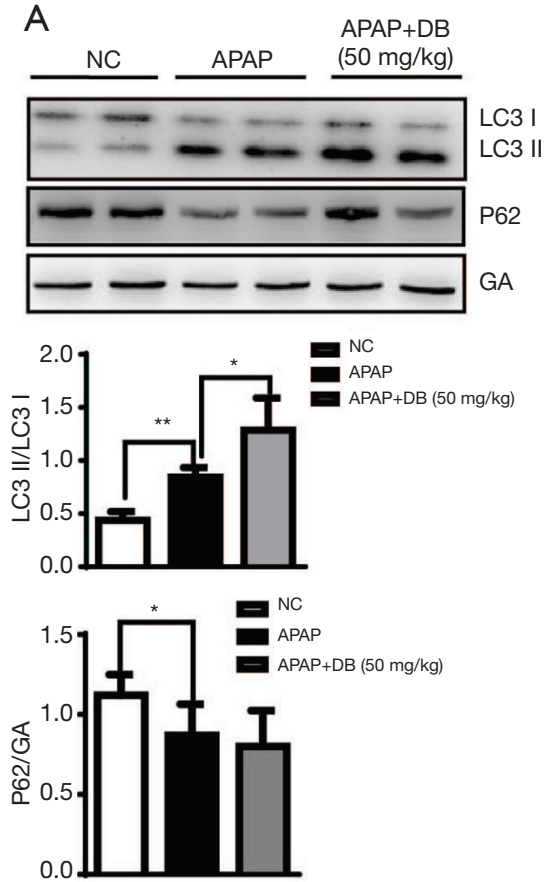
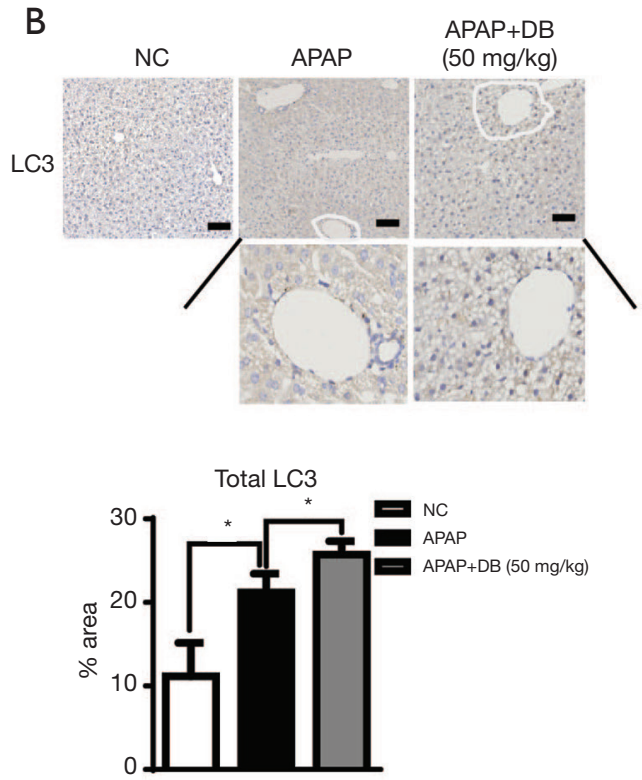

C
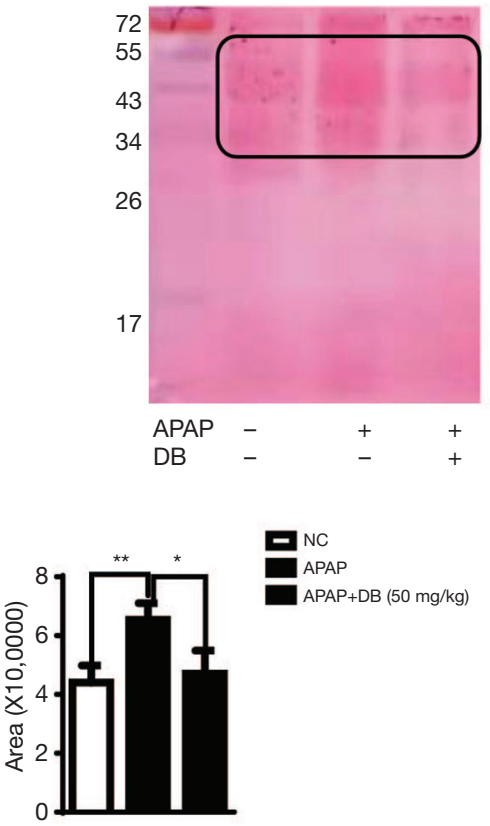

Figure 2 Activation of autophagy by DB alleviated APAP-induced hepatotoxicity. (A) Total liver lysates were subjected to Western blot analysis for LC3 and P62 (n=4). (B) lysosome autophagy was examined by immunohistochemistry. LC3 was increased in DB-treated APAPmice $(\mathrm{n}=3)$, scale bar $=50 \mu \mathrm{m}$. (C) Mice liver was subjected to Western blot analysis for APAP-AD. The membrane for the liver samples was further stained with Poncea red $(\mathrm{n}=3)$. *, $\mathrm{P}<0.05 ;{ }^{* *}, \mathrm{P}<0.01$.
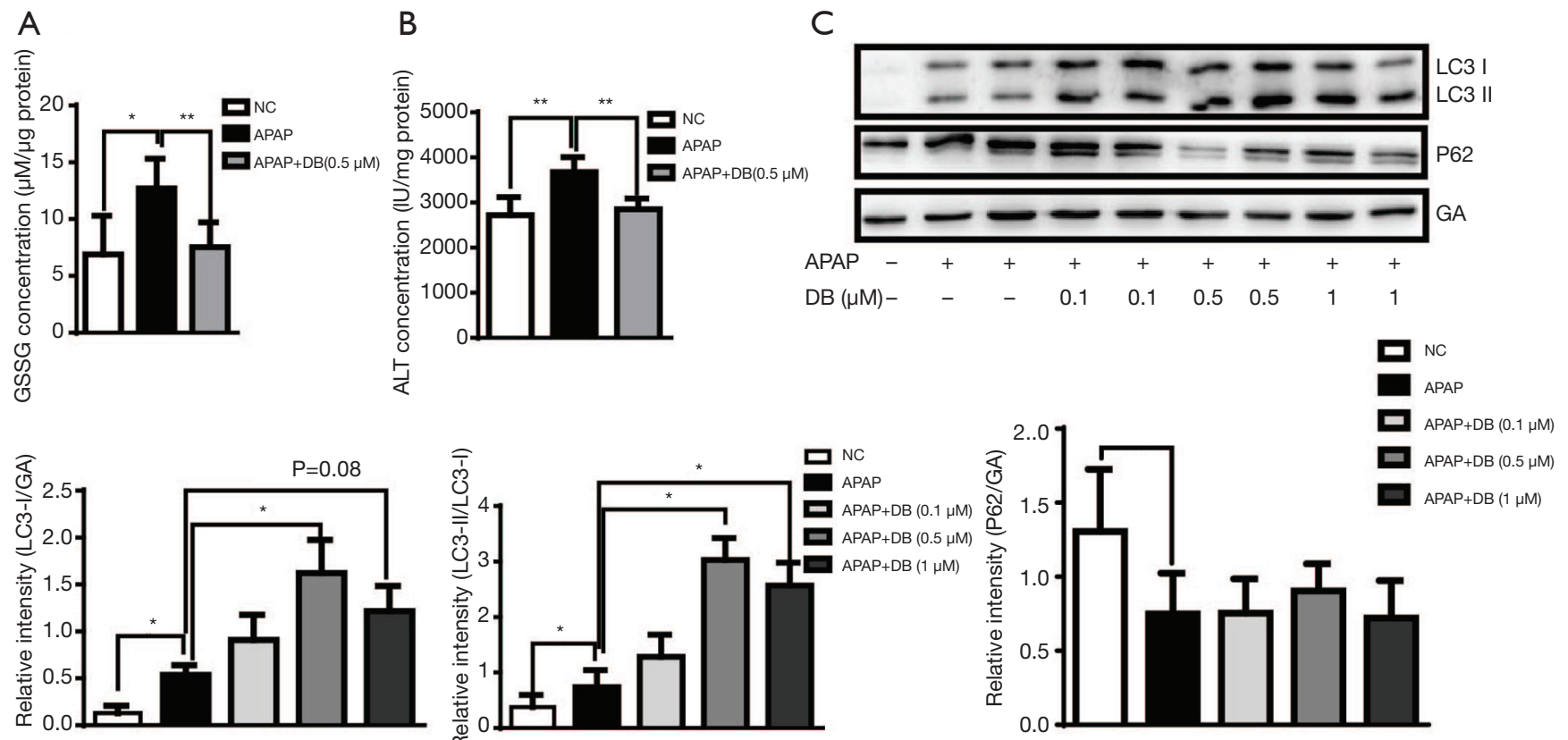

Figure 3 The inhibitory effects of DB treatment in APAP-induced hepatotoxicity. (A) Total content of GSSG in APAP-treated HepG2 cells with or without DB was measured after $12 \mathrm{~h}(\mathrm{n}=7)$. (B) The effect of DB treatment on ALT levels in APAP-induced HepG2 cells $(\mathrm{n}=6)$. (C) Total cell lysate was subjected to Western blot analysis for LC3 and P62 (n=4). (D) Relative intensity of LC3 and P62. *, P<0.05; **, P<0.01. 


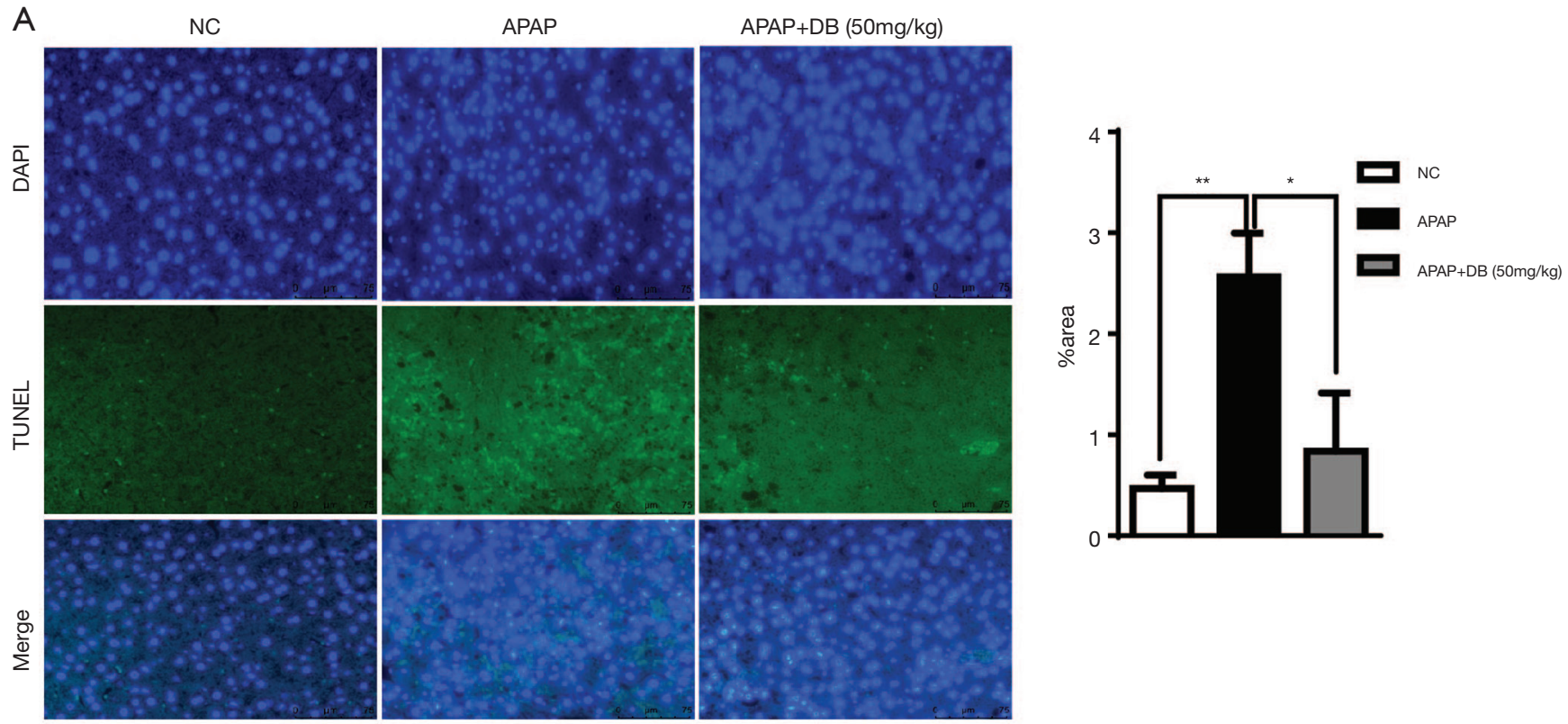

B

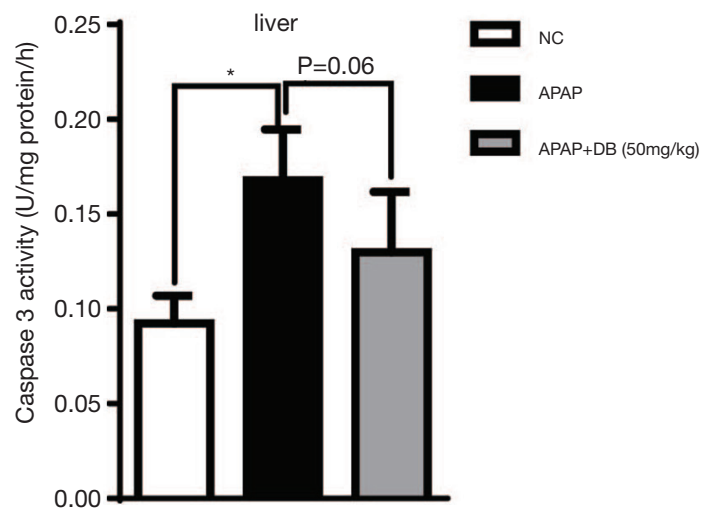

C

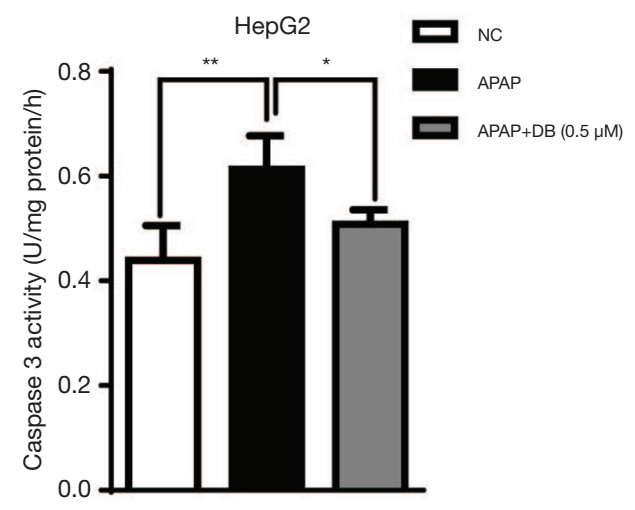

Figure 4 DB pretreatment suppressed apoptosis caused by APAP. (A) TUNEL staining of apoptotic hepatocytes counterstained with DAPI in liver tissue sections from mice treated with Vehicle (Control group), APAP (Model group), APAP + DB ( $50 \mathrm{mg} / \mathrm{kg})$ for $4 \mathrm{~h}$ ( $\mathrm{n}=3$, original magnifications, $\times 200$ ). (B) Capase 3 activity in liver tissues from mice treated with Vehicle (Control group), APAP (Model group), APAP + DB $(50 \mathrm{mg} / \mathrm{kg})$ for $4 \mathrm{~h}(\mathrm{n}=6)$. (C) Capase3 activity in HepG2 cells treated with Vehicle (Control group), APAP (Model group), APAP + DB $(0.5 \mu \mathrm{M})$ for $12 \mathrm{~h}(\mathrm{n}=5) .{ }^{*}, \mathrm{P}<0.05 ;{ }^{* *}, \mathrm{P}<0.01$.

\section{DB suppressed APAP-induced hepatocyte apoptosis in vitro and in vivo}

It has been reported that hepatocyte apoptosis is involved in the development of acute liver injury (28). To confirm the effects of DB on apoptosis induced by APAP both in vivo and in vitro, we performed TUNEL staining to evaluate apoptosis level in liver tissue sections, and examined the Caspase 3 activity both in liver tissue and HepG2 cells induced by APAP. We found that the number of TUNELpositive hepatocytes in APAP group was significantly higher than the control group, while DB pretreatment effectively decreased the number of TUNEL-positive hepatocytes, indicating that DB significantly inhibited APAP induced apoptosis (Figure 4A). Consistent with the TUNEL assay results, DB treatment suppressed Caspase 3 activity in mice and HepG2 cells caused by APAP (Figure 4B,C). 


\section{DB prevented the increase in bepatic Neu1 level due to APAP treatment}

Maintenance of the structural and functional integrity of lysosomes is vital for autophagosome-lysosome fusion. Neu1 is mainly located in lysosome, and acts as a negative regulator of lysosome exocytosis in hematopoietic cells by removal of sialic acids on LAMP-1 (17). We found that mRNA and protein levels of Neu1 were increased in both HepG2 cells and liver of mice by APAP induction. Treatment with $0.5 \mu \mathrm{M}$ (in vitro) and $50 \mathrm{mg} / \mathrm{kg}$ (in vivo) $\mathrm{DB}$ inhibited the elevation of Neu1 level (Figure $5 A, B, C, D$ ). But DB showed no significant effect on Neu1 level in Huh7 and SMMC-7721 HCC cells induced by APAP (Figure $S 2 A, S 2 B$ ). This phenotype may be caused by the lower Neu1 level in these cells compared to HepG2 cells (Figure S2C). We further tested whether enzyme activity of Neu1was also changed by APAP in vitro and in vivo. Our results demonstrated that $\mathrm{DB}(0.5 \mu \mathrm{M}$ in vitro and $50 \mathrm{mg} / \mathrm{kg}$ in vivo) prevented the increase of Neu1 activity caused by APAP (Figure $5 E, F)$. In line with this, DB $(0.5 \mu \mathrm{M}$ in vitro and $50 \mathrm{mg} / \mathrm{kg}$ in vivo) restored the level of lysosome marker (LAMP1) (Figure 5G,H). These data suggested that DB could restore the structural integrity of lysosome in ALF through inhibition of Neu1.

\section{Neu1 is a negative regulator of autophagy}

The above results indicated that the inhibition of Neu1 plays a role in protecting against APAP-induced hepatotoxicity through autophagy. In order to confirm the role of Neu1 in autophagy, we treated mice with Neu1 inhibitor-Oseltamivir (OS, $25 \mathrm{mg} / \mathrm{kg}$ ) $1 \mathrm{~h}$ before APAP induction. Histological analyses revealed that centrilobular necrosis in the necrotic area was markedly decreased in OS-treated mice compared to APAP-treated mice (Figure 6A). The predominant forms of APAP-AD (34$60 \mathrm{kD})$ were also reduced in the liver of OS-treated mice (Figure 6B). To investigate whether Neu1 was involved in autophagy, we treated HepG2 cells with Torin 1 (an mTOR inhibitor and autophagy inducer, $10 \mu \mathrm{M})$ or OS $(0.25 \mu \mathrm{M})$ $1 \mathrm{~h}$ before APAP induction. As shown in Figure $6 C$ and $6 D$, enzyme activity and protein level of Neu1 were both downregulated in Torin 1-treated and OS-pretreatment HepG2 cells, which was consistent with DB $(0.5 \mu \mathrm{M})$ treated HepG2 cells. In line with these observations, ALT levels were reduced in DB-, OS- and Torin1-treated HepG2 cells by APAP induction (Figure 6E), which indicated that DB ameliorated the hepatotoxic effects of APAP via inhibition of Neu1 activity. To investigate whether Neu1 alteration is correlated with autophagy, we checked LC3 and P62 level in OS or Torin1 pretreated HepG2 induced by APAP. OS and Torin 1 significantly promoted the LC3-II caused by APAP, but without markedly effect for P62 (Figure $6 F)$. Taken together, these above results lend credence to the hepatoprotective potential of DB particularly against APAP-induced acute liver injury.

\section{$D B$ alleviated acute liver injury induced by APAP via inbibition of Akt/mTOR signal}

$\mathrm{PI} 3 \mathrm{k} / \mathrm{Akt} / \mathrm{mTOR}$ signal is a classical signal pathway for autophagy regulation (29). As shown in Figure 6E, Torin1(mTOR inhibitor) significantly reduced the ALT in APAP-induced HepG2 cells, we confirmed whether DB protected against APAP hepatotoxicity via Akt/mTOR signal. We assessed the hepatic protein expression levels of Akt, p-Akt, mTOR, p-mTOR. The level of p-Akt and $\mathrm{p}$-mTOR were both elevated in APAP group but reduced after DB administration (Figure 7A). Our results indicated that APAP-induced ALF might be due to the alterations in Akt/mTOR pathway in the liver.

Neu1 is a negative regulator of lysosomal exocytosis. We also tested whether DB alleviated liver injury by directly targeting Neu1. Molecular docking experiment showed that DB docked into the cavity of protein Neu1, with the possibility of forming hydrogen-bond with six amino acid residues (TYR370, ARG280, GLU264, ASP226, SER102, and ALA162). The binding energy predicted by Autodock was $-7.86 \mathrm{kcal} / \mathrm{mol}$ (Figure $7 B$ ). Consistent with this, DB has no significant impact on autophagy in Huh7 and SMMC-7721 HCC cells with lower neu1 level (Figure $S 2 A, S 2 B$ ). The aforementioned observation indicated that DB could directly inhibit Neu1 activity.

\section{Discussion}

APAP-induced liver injury is one of the major causes of acute liver failure in clinical practice (30). The present work evaluated the protective effects of DB against ALF induced by APAP. The major findings of this study are as follows: (I) DB reduced APAP-induced hepatotoxicity both in vivo $(50 \mathrm{mg} / \mathrm{kg})$ and in vitro $(0.5 \mu \mathrm{M})$; (II) the hepatoprotective effect of DB was mediated through the activation of autophagy and inhibition of apoptosis by Akt/mTOR signal pathway; (III) DB restored the equilibrium of lysosome 
A

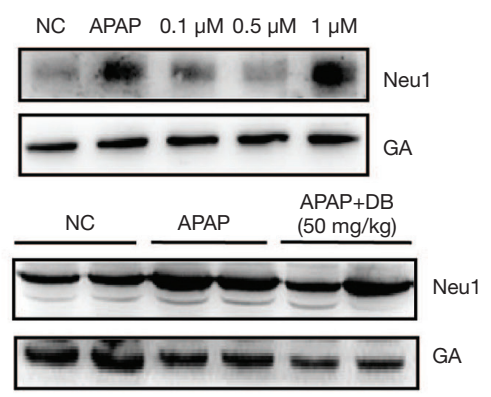

D

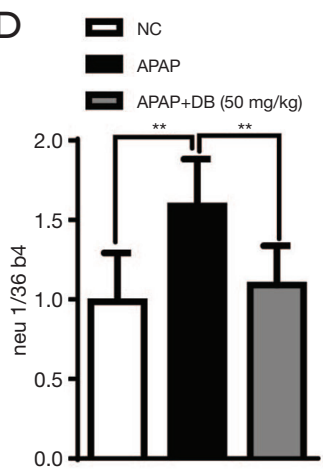

G
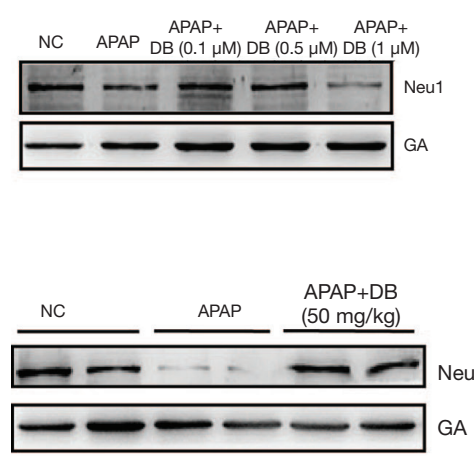

E
B

- NC

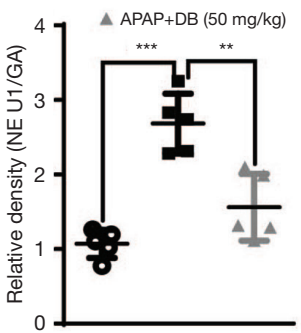

C

DAPAP+DB (0.5 $\mu \mathrm{M})$

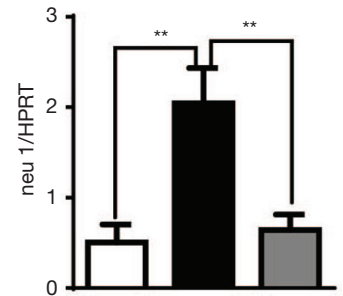

$\mathrm{F}$
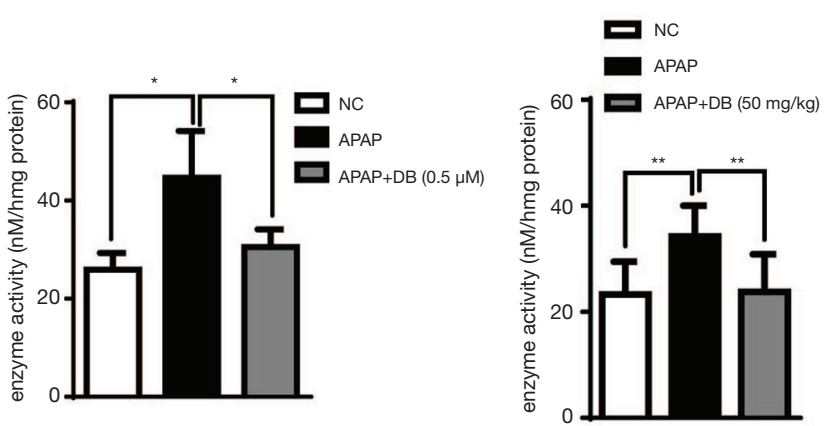

$\mathrm{H}$
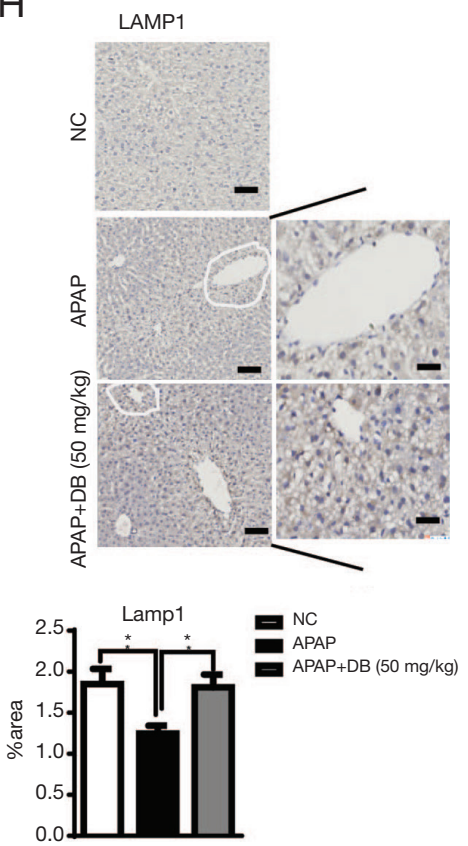

Figure 5 DB restored the increase of Neu1 in APAP-induced hepatotoxicity. (A) Protein levels of Neu1 were decreased in APAP-treated HepG2 cells $(n=3)$ and mice $(n=8)$ treated with DB by Western Blot. (B) Relative density of Neu1 in liver of APAP-treated mice by Western Blot. (C and D) Transcript levels of Neu1 were decreased in APAP-treated HepG2 cells ( $\mathrm{n}=4)$ and mice ( $\mathrm{n}=6-8)$ treated with DB by qRT-PCR. (E and F) Enzyme activity of Neu1 were inhibited in APAP-treated HepG2 cells and mice treated with DB (n=6-8). (G) Total cell lysate and liver lysates were subjected to Western blot analysis for LAMP1 (n=4). (H) lysosome marker was examined by immunohistochemistry. LAMP1 was increased in DB treated mice $(\mathrm{n}=3)$, scale bar $=50 \mu \mathrm{m} .{ }^{*}, \mathrm{P}<0.05 ;{ }^{* *}, \mathrm{P}<0.005 ;{ }^{* * *}, \mathrm{P}<0.001$. 
A

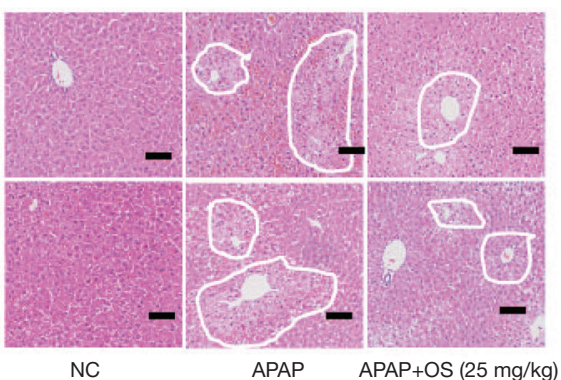

B

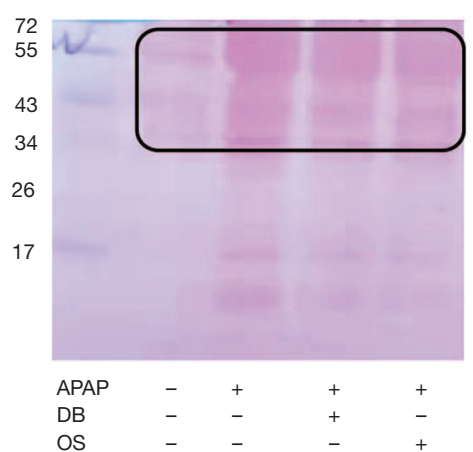

$\mathrm{F}$
C

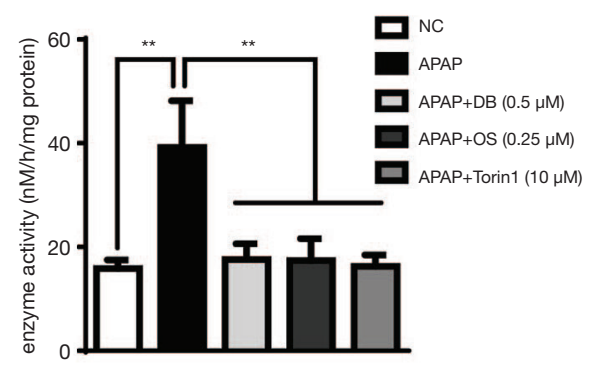

D

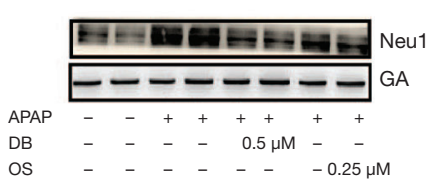

$=\mathrm{E}=\mathrm{ENeu1}$

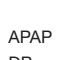

$\mathrm{DB}$

Torin1 - $-{ }_{-}-0.5 \mu \mathrm{M}-$

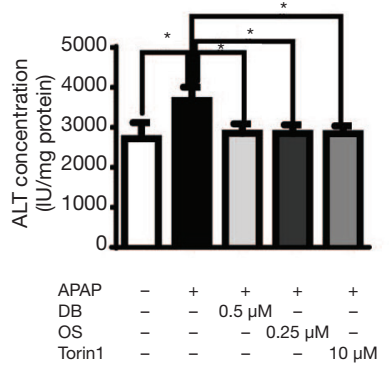

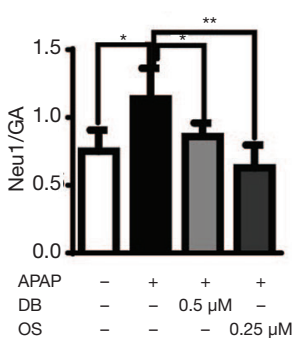
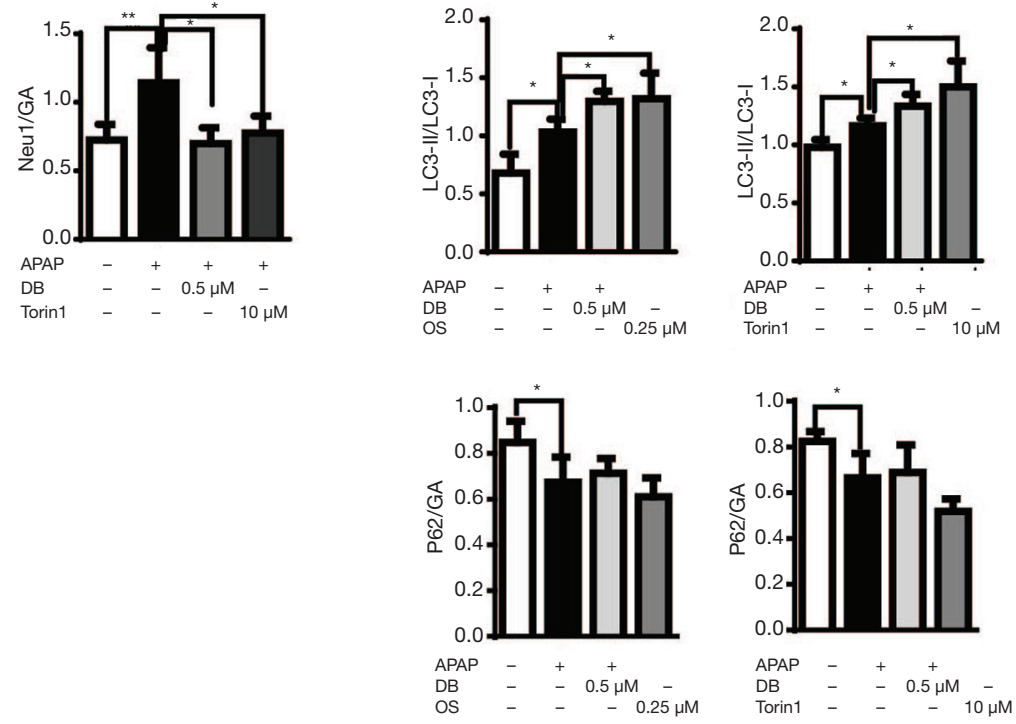

Figure 6 Neu1 negatively regulated autophagy in ALF. (A) Representative photomicrographs of liver samples of mice subjected to hematoxylin and eosin staining (magnification, $\times 10 ; n=5$, Scale Bars: $50 \mu \mathrm{m}$ ). (B) Liver samples of mice were subjected to Western blot analysis for APAP-AD. The membrane for the liver samples was further stained with Poncea red ( $\mathrm{n}=3)$. (C) Protein levels of Neu1 were decreased in APAP-treated HepG2 cell (n=3) upon treatment with OS and Torin1 as captured through Western blot analysis. (D) Enzyme activity of Neu1 was decreased in APAP-treated HepG2 cells $(\mathrm{n}=6)$ treated with OS and Torin1. (E) The effect of OS and Torin1 treatment on ALT levels in APAP-treated HepG2 cells (n=6). (F) Protein levels of LC3 and P62 in APAP-treated HepG2 cells subsequently treated with OS and Torin 1 as evidenced by Western blot analysis $(\mathrm{n}=4) .{ }^{*}, \mathrm{P}<0.05 ;{ }^{* *}, \mathrm{P}<0.005$. 

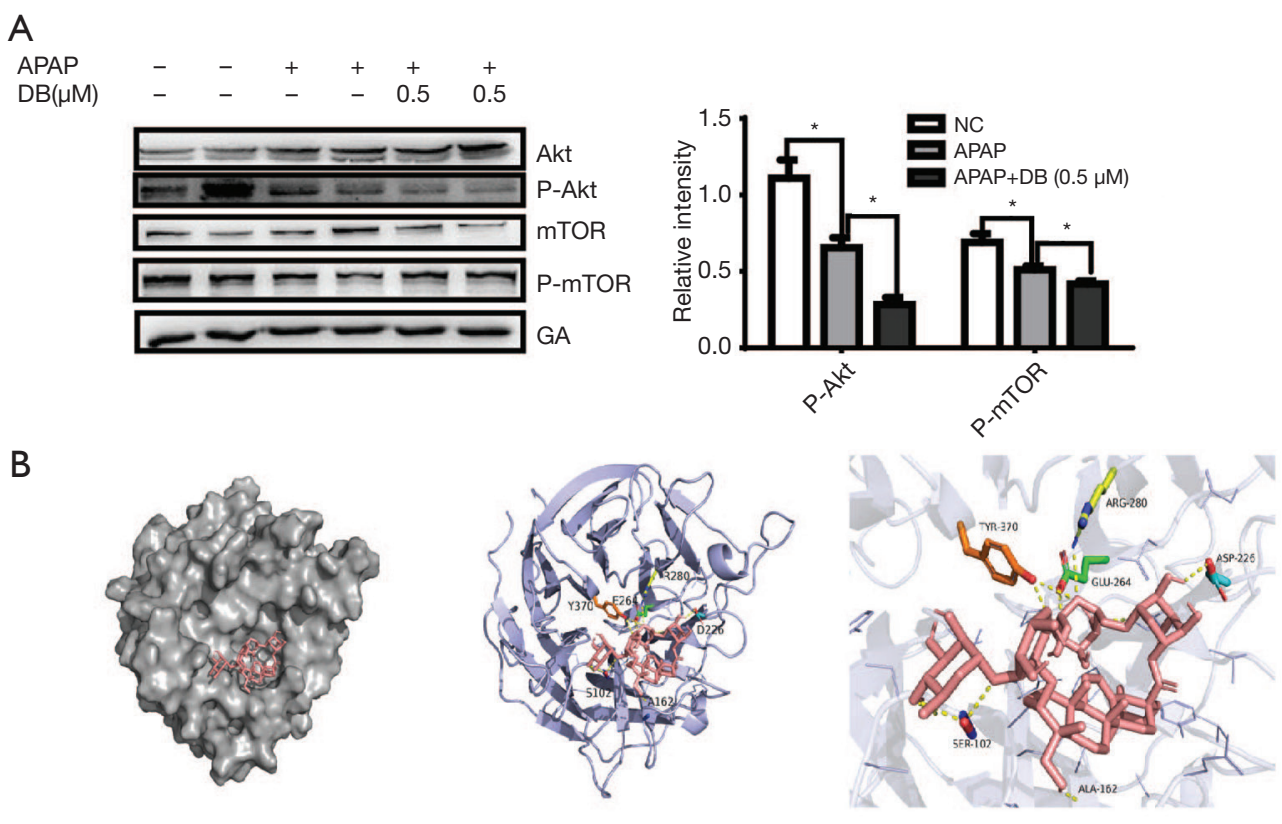

$E(D B-N e u 1)=-7.81 \mathrm{kal} / \mathrm{mol}$

Figure 7 DB ameliorated hepatotoxicity via interaction with Neu1. (A) Protein levels of P-AKT and p-mTOR were decreased in APAPtreated HepG2 cell with DB as captured through Western blot analysis. $(\mathrm{n}=4)\left({ }^{*}, \mathrm{P}<0.05\right)$. (B) Protein is shown as cartoon and DB as sticks. TYR370, ARG280, GLU264, ASP226, SER102, and ALA162 with important interactive hydrogen-bonds with DB are labeled, and the dashed lines represent hydrogen bonds. The binding energy $=-7.86 \mathrm{kcal} / \mathrm{mol}$.

structure by inhibiting Neu1 activity in APAP-induced liver damage.

Mitochondrial damage and APAP-AD formation are critical factors for APAP-induced hepatocyte necrosis. Various lines of evidence have shown that pharmacological induction of autophagy by Torin 1 offers protection against APAP-induced ALF by the removal of damaged mitochondria and APAP-AD $(10,11)$. However, the mechanisms that underlie this activity of the hepatocytes remain largely unclear. Phosphatase and tensin homolog (PTEN)-induced kinase 1 (PINK1), a mitochondrial serine/threonine kinase, mediates Ser65 phosphorylation of ubiquitin and enhances Parkin E3 ligase activity to facilitate mitophagy in ALF induced by APAP (31-33). Emerging evidence indicates that autophagy receptor protein-SQSTM1/p62 binds directly with LC3 via its LC3interaction region (LIR), and thus promotes recruitment of autophagosomes to mitochondria $(34,35)$. P62 has been reported to bind with APAP-AD and facilitate APAP$\mathrm{AD}$ transition to the detergent insoluble form, which can only be removed by autophagy (11). In the present study, histological analysis and Ponceau red staining showed that DB enhanced the removal of APAP-AD (34-60 kD) leading to protection against APAP-induced necrosis. Pretreatment with DB improved the level of LC3-II in APAP-induced hepatotoxicity model, suggesting that activation of autophagy played a key role in the hepatoprotective effect of DB. Excessive autophagy may cause apoptosis in pathological conditions, but our study revealed that DB moderately promoted autophagy in APAP injury model without increase of apoptosis, supplementation of DB partially inhibited activity of Caspase 3 and prevented DNA damage caused by APAP. Our results were supported by Gong's study, who reported that ASD (with one more rhamnose compared to DB could protect against apoptosis and activated autophagy in liver of NAFLD mice (23).

Neu1, the most abundant sialidase in mammals, is involved in the regulation of energy homeostasis, inflammation, proliferation, cell adhesion, phagocytosis, and exocytosis $(36,37)$. Neu1 regulates LAMP-1, a structural component of the lysosomal membrane, via its sialic acid cleavage. Hypersialylated LAMP-1 has a longer half-life and accumulates at plasma membrane, which is correlated with excessive lysosomal exocytosis of serine proteases in o mice bone (16). Our results revealed the function of Neu1 in APAP-induced ALF mice models those were pretreated 
with DB. Compared to HepG2 cells, SMMC-7721 and Huh7 HCC cells showed lower Neu1, which exhibited no significant change of Neu1 and autophagy marker by APAP and DB treatment, and cells with lower Neu1 level are more resistant to APAP injury. Taken together, our data demonstrate that DB ameliorated the hepatotoxic effects of APAP by regulating lysosome mediated autophagy through Neu1 inhibition. The AutoDock result showed that DB could bind with protein Neu1, which may be the cause of Neul enzyme activity variation by $\mathrm{DB}$. Moreover, how $\mathrm{DB}$ influences the protein level of Neu1 both in vitro and in vivo still needs further study.

It is generally accepted that defective autophagy results in excessive inflammation that contributes to disease pathology $(37,38)$. And Neu1 was positive enhancers of inflammation in monocytes/macrophages for atherosclerosis (39). LPS/D-Gal-induced acute liver injury mainly results from the release of massive inflammatory cytokines, such as interleukin (IL)- $1 \beta$, IL-6, and tumor necrosis factor (TNF)- $\alpha$. We found that $50 \mathrm{mg} / \mathrm{kg}$ DB can partly inhibited the elevation of AST, ALT and inflammatory infiltration by LPS/D-Gal. Whether higher dose of DB can significantly reverse the LPS/D-Gal-induced acute liver injury is needs deeply study. It has been confirmed that activation of autophagy by pharmacotherapy can protect against acute liver injury induced by various stimulus has been confirmed $(11,28,40)$. It is beneficial for the treatment of acute liver injury through restore the dysfunction of autophagy. We identified DB as a factor that exerted hepatoprotective activity through possible mechanisms involved in the inhibition of Neu1 and induction of autophagy.

\section{Conclusions}

In summary, our results identified a critical role of autophagy and Neu1 in the hepatoprotective effects of DB in APAP-induced hepatotoxicity models. DB inhibited liver toxicity through regulation of autophagy, basically via increasing the removal of APAP-AD, and thus preventing hepatic necrosis. Furthermore, the inhibition of Neu1 by DB could restore the excessive lysosome exocytosis. Therefore, Neul inhibition may be a new target for treating APAPinduced liver injury as exemplified with DB treatment.

\section{Acknowledgments}

The authors thank Dr. Raphael N. Alolga, a native English teacher for editing our manuscript. We thank YingJian Hou and Minhui Sun from the Cellular and Molecular Biology Center of China Pharmaceutical University for their technical help in histological microscopy and qRT-PCR. Funding: This project funded by China Postdoctoral science foundation (Grant No. 2018M630640) and the National Natural Science Foundation of China (Grant No. 81900780).

\section{Footnote}

Reporting Checklist: The authors have completed the ARRIVE reporting checklist. Available at http://dx.doi. org/10.21037/atm-19-3850

Data Sharing Statement: Available at http://dx.doi. org/10.21037/atm-19-3850

Conflicts of Interest: All authors have completed the ICMJE uniform disclosure form (available at http://dx.doi. org/10.21037/atm-19-3850). The authors have no conflicts of interest to declare.

Ethical Statement: The authors are accountable for all aspects of the work in ensuring that questions related to the accuracy or integrity of any part of the work are appropriately investigated and resolved. All experiments were approved by the Animal Ethics Committees of China Pharmaceutical University and performed in adherence with the Guide for the Care and Use of Laboratory Animals of China Pharmaceutical University.

Open Access Statement: This is an Open Access article distributed in accordance with the Creative Commons Attribution-NonCommercial-NoDerivs 4.0 International License (CC BY-NC-ND 4.0), which permits the noncommercial replication and distribution of the article with the strict proviso that no changes or edits are made and the original work is properly cited (including links to both the formal publication through the relevant DOI and the license). See: https://creativecommons.org/licenses/by-nc-nd/4.0/.

\section{References}

1. Larson AM. Acetaminophen hepatotoxicity. Clin Liver Dis 2007;11:525-48, vi.

2. Ramachandran A, Jaeschke H. Acetaminophen Toxicity: Novel Insights Into Mechanisms and Future Perspectives. Gene Expr 2018;18:19-30. 
3. Saito C, Zwingmann C, Jaeschke H. Novel mechanisms of protection against acetaminophen hepatotoxicity in mice by glutathione and $\mathrm{N}$-acetylcysteine. Hepatology 2010;51:246-54.

4. McGill MR, Sharpe MR, Williams CD, et al. The mechanism underlying acetaminophen-induced hepatotoxicity in humans and mice involves mitochondrial damage and nuclear DNA fragmentation. J Clin Invest 2012;122:1574-83.

5. Klionsky DJ, Emr SD. Autophagy as a regulated pathway of cellular degradation. Science 2000;290:1717-21.

6. Czaja MJ, Ding WX, Donohue TM, et al. Functions of autophagy in normal and diseased liver. Autophagy 2013;9:1131-58.

7. McGill MR, Lebofsky M, Norris HRK, et al. Plasma and liver acetaminophen-protein adduct levels in mice after acetaminophen treatment: Dose-response, mechanisms, and clinical implications. Toxicol Appl Pharmacol 2013;269:240-9.

8. Fan C, Tang X, Ye M, et al. Qi-Li-Qiang-Xin Alleviates Isoproterenol-Induced Myocardial Injury by Inhibiting Excessive Autophagy via Activating AKT/mTOR Pathway. Front Pharmacol 2019;10:1329.

9. Liu J, Ren YJ, Hou YL, et al. Dihydroartemisinin Induces Endothelial Cell Autophagy through Suppression of the Akt/mTOR Pathway. J Cancer 2019;10:6057-64.

10. Heard KJ, Green JL, James LP, et al. Acetaminophencysteine adducts during therapeutic dosing and following overdose. BMC Gastroenterol 2011;11:20.

11. Ni HM, McGill MR, Chao XJ, et al. Removal of acetaminophen protein adducts by autophagy protects against acetaminophen-induced liver injury in mice. J Hepatol 2016;65:354-62.

12. Dridi L, Seyrantepe V, Fougerat A, et al. Positive Regulation of Insulin Signaling by Neuraminidase 1 . Diabetes 2013;62:2338-46.

13. Fougerat A, Pan X, Smutova V, et al. Neuraminidase 1 activates insulin receptor and reverses insulin resistance in obese mice. Mol Metab 2018;12:76-88.

14. Nakatogawa H, Suzuki K, Kamada Y, et al. Dynamics and diversity in autophagy mechanisms: lessons from yeast. Nat Rev Mol Cell Biol 2009;10:458-67.

15. Parzych KR, Klionsky DJ. An Overview of Autophagy: Morphology, Mechanism, and Regulation. Antioxid Redox Signal 2014;20:460-73.

16. Yogalingam G, Bonten EJ, van de Vlekkert D, et al. Neuraminidase 1 is a negative regulator of lysosomal exocytosis. Dev Cell 2008;15:74-86.
17. Qi B, Zhang S, Guo D, et al. Protective effect and mechanism of ginsenoside $\mathrm{Rg} 1$ on carbon tetrachlorideinduced acute liver injury. Mol Med Rep 2017;16:2814-22.

18. Craig DGN, Ford AC, Hayes PC, et al. Systematic review: prognostic tests of paracetamol-induced acute liver failure. Aliment Pharmacol Ther 2010;31:1064-76.

19. Adebayo D, Mookerjee RP, Jalan R. Mechanistic biomarkers in acute liver injury: Are we there yet? J Hepatol 2012;56:1003-5.

20. Ning C, Gao X, Wang C, et al. Protective effects of ginsenoside $\operatorname{Rg} 1$ against lipopolysaccharide/ D-galactosamine-induced acute liver injury in mice through inhibiting toll-like receptor 4 signaling pathway. Int Immunopharmacol 2018;61:266-76.

21. Lin L, Que R, Shen Y, et al. Saikosaponin-d alleviates carbon-tetrachloride induced acute hepatocellular injury by inhibiting oxidative stress and NLRP3 inflammasome activation in the HL-7702 cell line. Mol Med Rep 2018;17:7939-46.

22. Singh H, Sidhu S, Chopra K, et al. The novel role of betaaescin in attenuating $\mathrm{CCl}$-induced hepatotoxicity in rats. Pharm Biol 2017;55:749-57.

23. Gong LL, Li GR, Zhang W, et al. Akebia Saponin D Decreases Hepatic Steatosis through Autophagy Modulation. J Pharmacol Exp Ther 2016;359:392-400.

24. Gong LL, Yang S, Zhang W, et al. Akebia saponin D alleviates hepatic steatosis through BNip3 induced mitophagy. J Pharmacol Sci 2018;136:189-95.

25. Pshezhetsky AV, Potier M. Association of $\mathrm{N}$-acetylgalactosamine-6-sulfate sulfatase with the multienzyme lysosomal complex of beta-galactosidase, cathepsin A, and neuraminidase. Possible implication for intralysosomal catabolism of keratan sulfate. J Biol Chem 1996;271:28359-65.

26. Zhang L, Wei TT, Li Y, et al. Functional Metabolomics Characterizes a Key Role for N-Acetylneuraminic Acid in Coronary Artery Diseases. Circulation 2018;137:1374-90.

27. Ni HM, Bockus A, Boggess N, et al. Activation of autophagy protects against acetaminophen-induced hepatotoxicity. Hepatology 2012;55:222-32.

28. Li L, Yin HY, Zhao Y, et al. Protective role of puerarin on LPS/D-Gal induced acute liver injury via restoring autophagy. Am J Transl Res 2018;10:957-65.

29. Liu W, Li S, Qu Z, et al. Betulinic acid induces autophagy-mediated apoptosis through suppression of the PI3K/AKT/mTOR signaling pathway and inhibits hepatocellular carcinoma. Am J Transl Res 2019;11:6952-64. 
30. Bernal W, Lee WM, Wendon J, et al. Acute liver failure: A curable disease by 2024? J Hepatol 2015;62:S112-20.

31. Vives-Bauza C, Zhou C, Huang Y, et al. PINK1-dependent recruitment of Parkin to mitochondria in mitophagy. Proc Natl Acad Sci U S A 2010;107:378-83.

32. Koyano F, Okatsu K, Kosako H, et al. Ubiquitin is phosphorylated by PINK1 to activate parkin. Nature 2014;510:162-6.

33. Chan NC, Salazar AM, Pham AH, et al. Broad activation of the ubiquitin-proteasome system by Parkin is critical for mitophagy. Hum Mol Genet 2011;20:1726-37.

34. Manley S, Williams JA, Ding WX. Role of p62/SQSTM1 in liver physiology and pathogenesis. Exp Biol Med (Maywood) 2013;238:525-38.

35. Katsuragi Y, Ichimura Y, Komatsu M. p62/SQSTM1 functions as a signaling hub and an autophagy adaptor. FEBS J 2015;282:4672-8.

36. Pshezhetsky AV, Ashmarina LI. Desialylation of

Cite this article as: Chen S, Li M, Jiang W, Zheng H, Qi LW, Jiang S. The role of Neu1 in the protective effect of dipsacoside $\mathrm{B}$ on acetaminophen-induced liver injury. Ann Transl Med 2020;8(13):823. doi: 10.21037/atm-19-3850 surface receptors as a new dimension in cell signaling. Biochemistry (Mosc) 2013;78:736-45.

37. Santeford A, Wiley LA, Park S, et al. Impaired autophagy in macrophages promotes inflammatory eye disease. Autophagy 2016;12:1876-85.

38. Cadwell K, Liu JY, Brown SL, et al. A key role for autophagy and the autophagy gene Atg1611 in mouse and human intestinal Paneth cells. Nature 2008;456:259-63.

39. Sieve I, Ricke-Hoch M, Kasten M, et al. A positive feedback loop between IL-1 beta, LPS and NEU1 may promote atherosclerosis by enhancing a pro-inflammatory state in monocytes and macrophages. Vascul Pharmacol 2018;103:16-28.

40. Lv H, Yang H, Wang Z, et al. Nrf2 signaling and autophagy are complementary in protecting lipopolysaccharide/d-galactosamine-induced acute liver injury by licochalcone A. Cell Death Dis 2019;10:313. 


\section{Methods}

\section{Reagents and chemicals}

LPS and D-gal were order from Solarbio Life Science (Beijing, China).

\section{Experimental animals}

18-22 g male C57BL/6J mice were housed in a specific pathogen-free facility under $12 \mathrm{~h}$ light- $12 \mathrm{~h}$ dark cycle. Mice were randomly assigned to four groups $(\mathrm{n}=6-8$ each group): (I) Normal control group: treated with saline by intraperitoneal injection, (II) LPS/D-gal induced group: treated with $40 \mu \mathrm{g} / \mathrm{kg}$ LPS and $700 \mathrm{mg} / \mathrm{kg} \mathrm{D}$-gal by intraperitoneal injection, (III) LPS/D-gal + DB group: $25 \mathrm{mg} / \mathrm{kg}$ DB was given by intraperitoneal injection $1 \mathrm{~h}$ before treated with $40 \mu \mathrm{g} / \mathrm{kg}$ LPS and $700 \mathrm{mg} / \mathrm{kg} \mathrm{D}$-gal,
(IV) APAP + DB group: $50 \mathrm{mg} / \mathrm{kg} \mathrm{DB}$ was given by intraperitoneal injection $1 \mathrm{~h}$ before treated with $40 \mu \mathrm{g} / \mathrm{kg}$ LPS and $700 \mathrm{mg} / \mathrm{kg}$ D-gal. All mice were sacrificed $4 \mathrm{~h}$ after different treatment. The animal care and all experimental procedures were approved by the Animal Ethics Committee of China Pharmaceutical University.

\section{Cell culture}

SMMC-7721(TCHu 52) and Huh7 (SCSP-526) were kindly provided by Stem Cell Bank, Chinese Academy of Sciences. SMMC-7721 and Huh7 cells were supported in Dulbecco's Modified Eagle Medium (DMEM, KGM31600500, KeyGEN BioTECH) supplemented with $10 \%$ fetal bovine serum (FBS). All of the cells were maintained at $37^{\circ} \mathrm{C}$ in a humidified atmosphere with $5 \% \mathrm{CO}_{2}$.
A

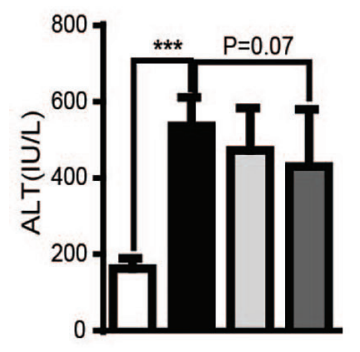

B

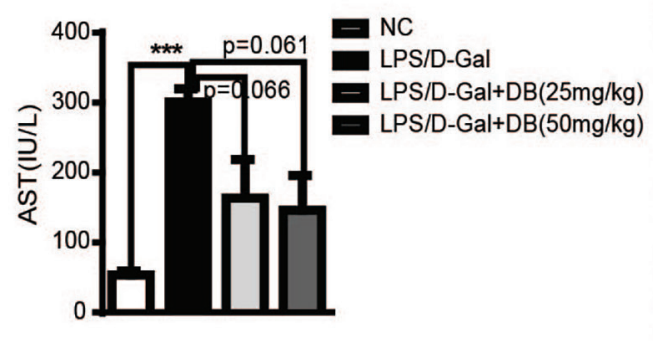

C NC

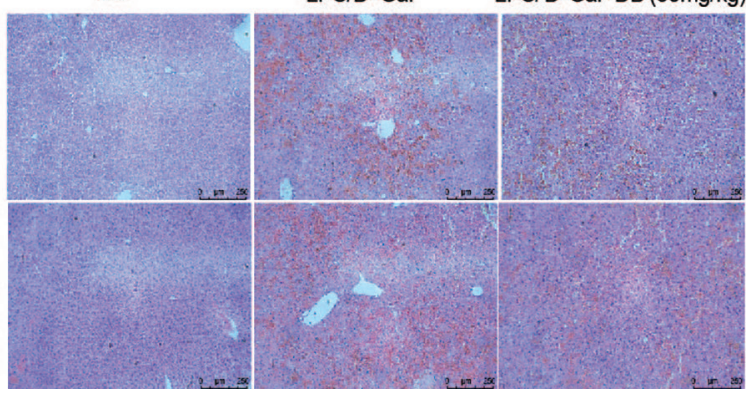

Figure S1 Protective effect of DB on LPS/D-gal induced mice. (A and B) Serum ALT and AST levels in LPS/D-gal -treated mice with or without DB were detected after LPS/D-gal treatment for $6 \mathrm{~h}$. (C) Representative liver histopathology with hematoxylin/eosin staining of LPS/D-gal -induced liver injury in mice, assessed by images captured by light microscope of liver sections (magnification, $\times 10$; $n=5$, scale bars: $100 \mu \mathrm{m}) . \mathrm{n}=6-8,{ }^{* * *}, \mathrm{P}<0.001$. 
A

SMMC7721

$\begin{array}{lcccccc}\mathrm{APAP} & - & + & + & + & + & + \\ \mathrm{DB}(\mu \mathrm{M}) & - & - & 0.1 & 0.5 & 1 & 10\end{array}$
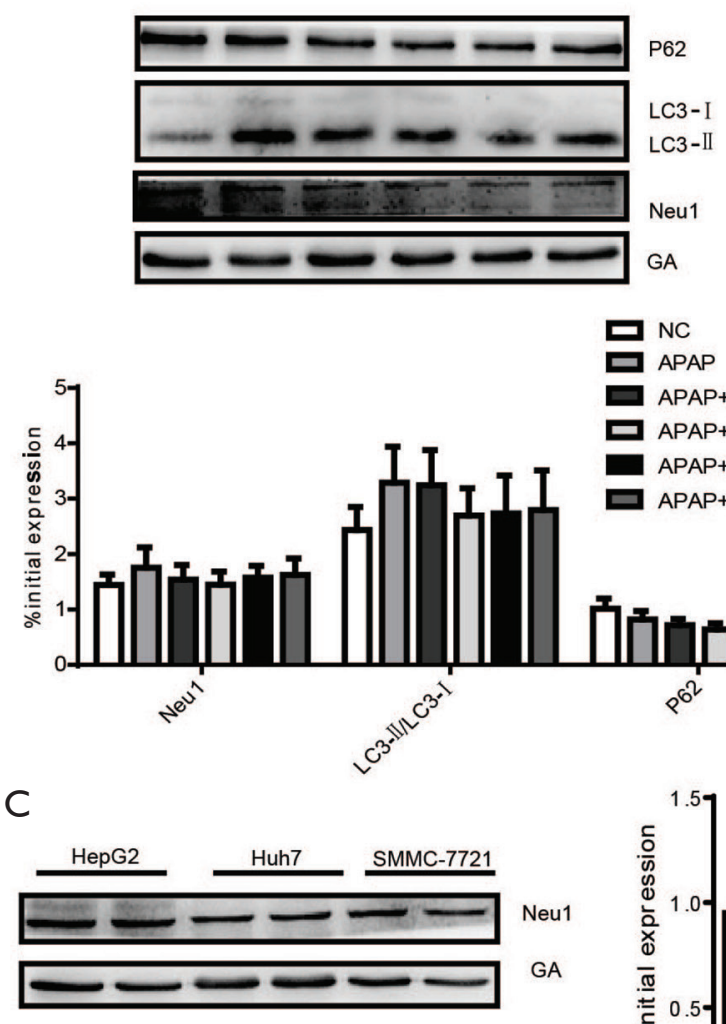

B
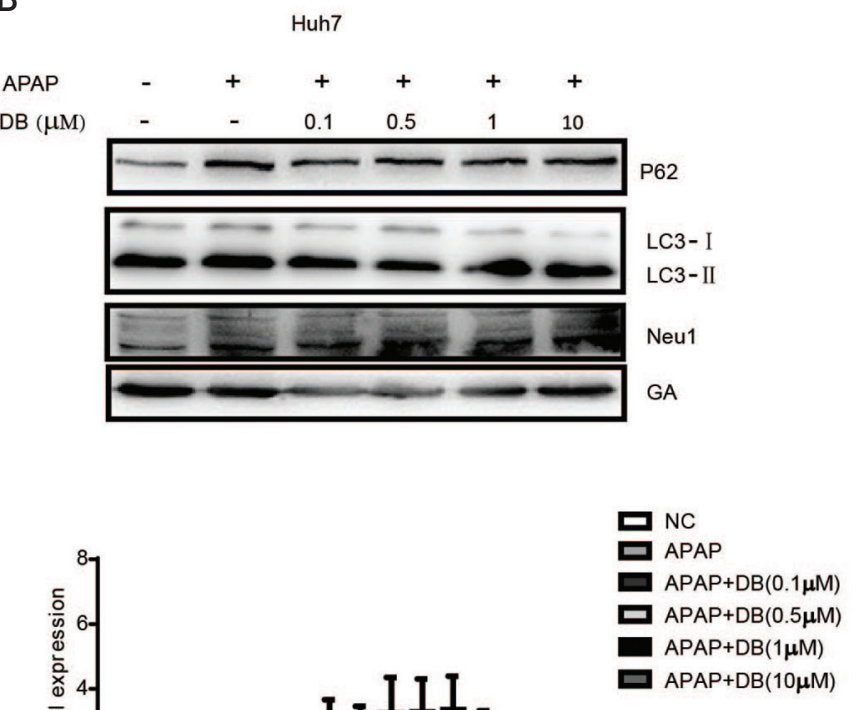

Figure S2 Autophagy level in different DB pretreatment HCC cell line by APAP induction. (A and B) Protein level and gray scale of p62 and LC3 was no significant change in APAP induced SMMC-7721 and Huh7 cells. (C) Neu1 expression in different HCC cell lines ( $\mathrm{n}=4$, *, $\left.\mathrm{P}<0.05 ;{ }^{* *}, \mathrm{P}<0.005\right)$. 